\section{Remission rates during treatment with venlafaxine or selective serotonin reuptake inhibitors}

\author{
MICHAEL E. THASE, A. RICHARD ENTSUAH and RICHARD L. RUDOLPH
}

The more commonly used measure of antidepressant efficacy in clinical trials has been a $50 \%$ reduction from baseline total scores on the Hamilton Rating Scale for Depression (HRSD) (Prien et al, 1991; Depression Guideline Panel, 1993). A more stringent measure of antidepressant efficacy is the ability to induce remission, a clinical state characterised by minimal residual symptoms (e.g. 17-item HRSD total scores of $\leqslant 7$; Frank et al, 1991). Patients treated to full remission are less likely to relapse (Thase et al, 1992; Fava et al, 1996) and have more normal psychosocial and vocational functioning (Miller et al, 1998) when compared with incompletely remitted patients. This report presents the results of a pooled analysis of remission rates comparing venlafaxine and three selective serotonin reuptake inhibitors (SSRIs): fluoxetine, paroxetine and fluvoxamine. It includes original data from 2045 patients with depression, drawn from eight related randomised controlled trials. We undertook this analysis to test the hypothesis that patients treated with venlafaxine, a serotonin-noradrenaline reuptake inhibitor (SNRI) (Muth et al, 1986), are significantly more likely to achieve remission than those treated with SSRIs.

\section{METHOD}

This analysis included data from the patients with depression who participated in the eight double-blind, randomised clinical trials comparing venlafaxine and SSRIs conducted by the Clinical Research and Development department at Wyeth-Ayerst Laboratories during the development of the immediate-release (IR) and extendedrelease (XR) formulations of venlafaxine. Results from four of these studies have been published (Clerc et al, 1994; Dierick et al, 1996; Silverstone et al, 1998; Rudolph \& Feiger, 1999). Results from two studies have been presented as posters and published in abstract form (Salinas et al, 1997; Rudolph et al, 1998a). The remaining two studies are unpublished (Studies 347 and 349; data on file, Wyeth-Ayerst Laboratories, Philadelphia, PA). The doses employed were: venlafaxine IR, 75-375 mg/day; venlafaxine XR, 75$225 \mathrm{mg} /$ day; fluoxetine, $20-80 \mathrm{mg} /$ day; paroxetine, $20-40 \mathrm{mg} /$ day; and fluvoxamine, $100-200 \mathrm{mg} /$ day. Four studies included a placebo control group (Salinas $e t$ al, 1997; Rudolph et al, 1998a; Silverstone et al, 1998; Rudolph \& Feiger, 1999). Each study was approved by the ethics committees of the participating sites and conducted according to the guidelines of the Declaration of Helsinki and its amendments. All patients provided written informed consent. Table 1 summarises the study characteristics.

\section{Patients}

Patients could be enrolled if they were at least 18 years old and met the criteria of the Diagnostic and Statistical Manual of Mental Disorders (DSM; American Psychiatric Association, 1987, 1994) for major depression (DSM-III-R) or major depressive disorder (DSM-IV) for at least 1 month. There were 68 in-patients (one study, Clerc et al, 1994) and 1977 outpatients; all patients had minimum scores of either 20 on the $\mathrm{HRSD}_{21}$ (Hamilton, 1960) or 25 on the MontgomeryÅsberg Depression Rating Scale (MADRS; Montgomery \& Åsberg, 1979) at both pre-study and baseline (study day -1 ), with no greater than a $20 \%$ decrease in severity between pre-study and baseline evaluations.

Patients with clinically significant cardiovascular, renal or hepatic disease, seizure disorders, a recent history of alcohol or drug misuse or clinically significant abnormalities on baseline physical examination, electrocardiogram (ECG) or laboratory tests were excluded from participation. Patients who were hypersensitive to the study drugs or had used any investigational or antipsychotic drug within 30 days, a monoamine oxidase inhibitor within 14 days or other antidepressant, anxiolytic, sedative-hypnotic or nonpsychopharmacological drugs with psychotropic effects within 7 days of double-blind treatment also were excluded. Chloral hydrate (maximum $2000 \mathrm{mg}$ ) or temazepam ( $20 \mathrm{mg}$; one study) were permitted as hypnotics. Table 2 summarises the 
Table I Studies pooled for analysis of the Hamilton Rating Scale for Depression remission $(n=8)$

\begin{tabular}{|c|c|c|c|c|}
\hline Study & Treatment & Dosage range (mean) & $\begin{array}{l}\text { Number of patients per study: all } \\
\text { patients }(n=2 \text { II7)/ITT }(n=2045)\end{array}$ & $\begin{array}{l}\text { Treatment duration } \\
\text { (weeks) }\end{array}$ \\
\hline \multirow[t]{3}{*}{ Rudolph \& Feiger, 1999 (Study 2II) } & Venlafaxine $X R$ & 75-225 mg/day (175) & $100 / 95$ & 8 \\
\hline & Fluoxetine & $20-60 \mathrm{mg} /$ day (47) & $103 / 103$ & \\
\hline & Placebo & & $98 / 97$ & \\
\hline \multirow[t]{3}{*}{ Silverstone et al, 1999 (Study 360) } & Venlafaxine $X R$ & $75-225 \mathrm{mg} /$ day $(|4|)$ & $|28 /| 2 \mid$ & $8^{2}$ \\
\hline & Fluoxetine & $20-60 \mathrm{mg} /$ day $(40)$ & $121 / 114$ & \\
\hline & Placebo & & $118 / 118$ & \\
\hline \multirow[t]{3}{*}{ Salinas et al, 1997 (Study 367) } & Venlafaxine $X R$ & $75-150$ mg/day $(75 / 150)^{\prime}$ & $165 / 161$ & 8 \\
\hline & Paroxetine & 20 mg/day (20) & $81 / 80$ & \\
\hline & Placebo & & $83 / 82$ & \\
\hline \multirow[t]{3}{*}{ Rudolph et al, 1998a (Study 372) } & Venlafaxine IR & $75-375 \mathrm{mg} /$ day $(318)$ & $156 / 144$ & 6 \\
\hline & Fluoxetine & 20-80 mg/day (NA) & $152 / 146$ & \\
\hline & Placebo & & $152 / 149$ & \\
\hline \multirow[t]{2}{*}{ Clerc et al, 1994 (Study 340) } & Venlafaxine IR & 100-200 mg/day (199) & $34 / 33$ & 6 \\
\hline & Fluoxetine & 20-40 mg/day (NA) & $34 / 34$ & \\
\hline \multirow[t]{2}{*}{ Study $347^{3}$} & Venlafaxine IR & $75-150 \mathrm{mg} /$ day (NA) & $77 / 77$ & 6 \\
\hline & Fluvoxamine & $100-200 \mathrm{mg} /$ day (NA) & $34 / 34$ & \\
\hline \multirow[t]{2}{*}{ Dierick et al, 1996 (Study 348) } & Venlafaxine IR & $75-150$ mg/day (II2) & $153 / 145$ & 8 \\
\hline & Fluoxetine & $20 \mathrm{mg} /$ day & $161 / 157$ & \\
\hline \multirow[t]{2}{*}{ Study $349^{3}$} & Venlafaxine IR & $75-150 \mathrm{mg} /$ day (NA) & $82 / 75$ & 8 \\
\hline & Paroxetine & 20-40 mg/day (NA) & $85 / 80$ & \\
\hline
\end{tabular}

I. This study employed 75 and $150 \mathrm{mg}$ fixed doses of venlafaxine $X R$.

2. This study lasted $I 2$ weeks but results are presented at week 8 for consistency.

3. Unpublished data on file, Wyeth-Ayerst Research, Philadelphia, PA.

IR, immediate-release formula; ITT, intent-to-treat patients; XR, extended-release formulation.

Table 2 Baseline characteristics of intent-to-treat patients (pooled studies, $n=2045$ )

\begin{tabular}{lccc}
\hline Characteristic & $\begin{array}{c}\text { Venlafaxine } \\
(n=85 I)\end{array}$ & $\begin{array}{c}\text { SSRI } \\
(n=748)\end{array}$ & $\begin{array}{c}\text { Placebo } \\
(n=446)\end{array}$ \\
\hline Mean age, years (s.d.) & $42(I 2)$ & $42(I 3)$ & $4 I(I I)$ \\
Women/men, \% & $65 / 35$ & $64 / 36$ & $62 / 38$ \\
Mean (s.d.) HRSD 2 total score & $26(5)$ & $26(4)$ & $26(4)$ \\
Mean (s.d.) MADRS total score & $3 I(5)$ & $3 I(5)$ & $30(5)$ \\
CGI-S score $>4$ (\%) & 53 & 53 & 361 \\
\hline
\end{tabular}

I. Studies utilising placebo enrolled significantly fewer patients with $\mathrm{CGI}-\mathrm{S}$ scores $>4(P<0.0 \mathrm{I})$. Across the placebo-controlled studies there was no difference between groups.

CGI-S, Clinical Global Impression - Severity of Illness; HRSD 21 , 2 I-item Hamilton Rating Scale for Depression; MADRS, Montgomery-Åsberg Depression Rating Scale; SSRI, selective serotonin reuptake inhibitor.

socio-demographic and pre-treatment clinical characteristics of the pooled study groups.

\section{Study drugs}

Patients were randomly assigned to treatment with venlafaxine $(n=865)$, an SSRI (fluoxetine, $n=563$; paroxetine, $n=160$; or fluvoxamine, $n=34$ ) or placebo (four studies only, $n=450$ ) during the doubleblind treatment period at the daily dosages shown in Table 1.

\section{Efficacy and safety assessments}

The HRSD, MADRS and Clinical Global Impression - Severity of Illness (CGI-S) (National Institute of Mental Health, 1985) were performed at study day -1 , prior to double-blind therapy. These measures (along with the CGI improvement score) were reassessed on study days 7,14 , $21,28,42$ and, if available, 56. Remission was defined as a total score of $\leqslant 7$ on the first 17 items of the HRSD (Frank et al, 1991).

Safety and tolerability were evaluated on the basis of adverse events that were recorded throughout the study evaluation period and changes that occurred in the physical examination, vital signs, 12-lead ECG recordings and clinical laboratory tests during treatment. For this report, only the proportions of patients withdrawn from double-blind therapy because of side-effects and lack of efficacy were compared.

\section{Statistical analyses}

The analyses were performed on data from a modified intent-to-treat sample, which included all patients who received at least one dose of study medication and had at least one HRSD evaluation during therapy. Remission rates were calculated using the last-observation-carried-forward (LOCF) 


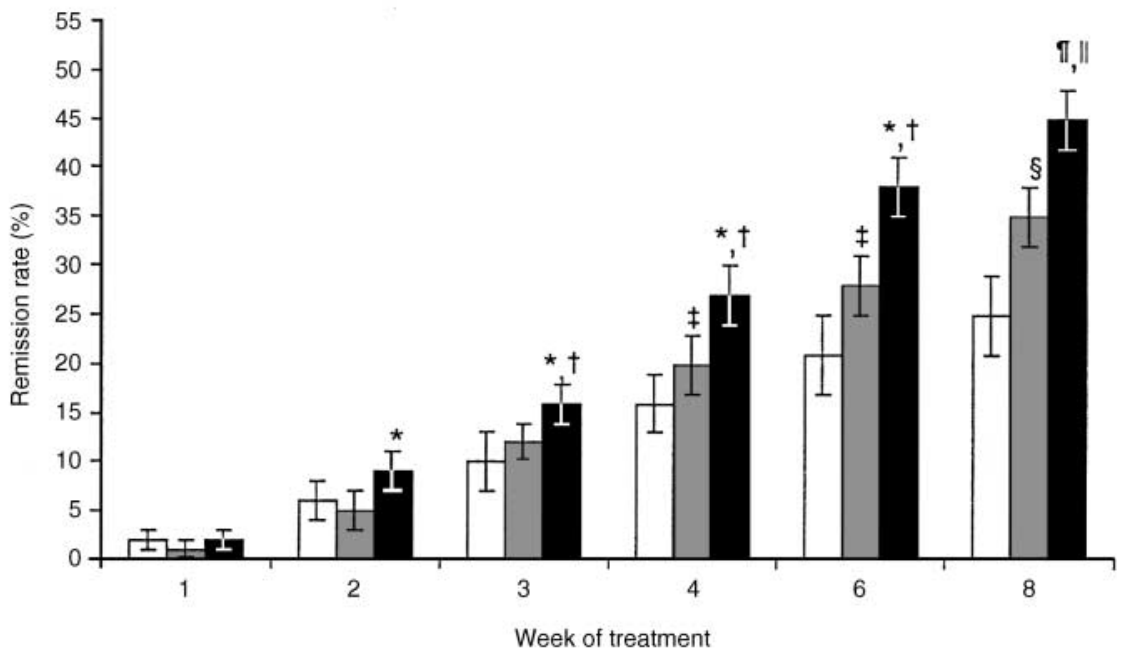

Fig. I Remission rates $\left(\mathrm{HRSD}_{17}\right.$ score $\leqslant 7 \pm 95 \% \mathrm{Cl}$ ) for pooled studies comparing venlafaxine (black bar), SSRI (grey bar) and placebo (white bar) treatments: $* P \leqslant 0.05$, venlafaxine $v$. SSRI; ${ }^{\dagger} P \leqslant 0.05$, venlafaxine $v$. placebo; ${ }^{\ddagger} P \leqslant 0.05$, SSRI v. placebo; ${ }^{\S} P<0.001$, SSRI v. placebo; ${ }^{\uparrow} P<0.001$, venlafaxine v. SSRI; $\| P<0.001$, venlafaxine $v$. placebo. $\mathrm{HRSD}_{17}$, I7-item Hamilton Rating Scale for Depression; SSRI, selective serotonin reuptake inhibitor.

method, which allowed the inclusion of patients who were withdrawn early. Pairwise comparisons of remission rates were made with Fisher's exact test. All tests of hypotheses were two-sided. Results of statistical analyses were considered significant when $P$ was $\leqslant 0.05$. The $95 \%$ confidence intervals (CIs) for differences in remission rates between groups were calculated for the pooled data at each interval. The odds ratios for remission with a 95\% CI (Rothman, 1986) were also calculated for venlafaxine or an SSRI $v$. placebo and for venlafaxine $v$. the SSRIs. Homogeneity of the odds ratios across studies was tested with the Breslow-Day test (Breslow \& Day, 1980).

Analyses of various subgroups were performed to corroborate the overall findings, including studies using the extended-release or immediate-release formulations, active-controlled studies, placebo-controlled studies, the single inpatient study, the seven out-patient studies and studies utilising fluoxetine $v$. those using other SSRIs. Additional analyses compared alternative definitions of remission to ensure the robustness of the findings. The following additional definitions were examined: $\mathrm{HRSD}_{21} \leqslant 7, \mathrm{HRSD}_{21}$ $\leqslant 8, \mathrm{HRSD}_{21} \leqslant 10, \mathrm{HRSD}_{17} \leqslant 10$ plus $\mathrm{CGI}=1$, MADRS $<10$, and $\geqslant 50 \%$ decrease from baseline $\mathrm{HRSD}_{21}$ scores. Finally, a sensitivity analysis was performed by removing each individual study from the pooled analysis, one at a time (Thase et al, 1997).

\section{RESULTS}

Among the 2117 patients enrolled, 2045 $(96.6 \%)$ were included in the intent-to-treat analyses of venlafaxine IR and venlafaxine XR $(n=851)$, the SSRIs $(n=748)$ and placebo $(n=446)$. Results from one investigational site (27 patients in total) were excluded prior to the analysis because the validity of the data could not be verified. The treatment groups had similar characteristics at baseline (see Table 2). However, patients enrolled in the four placebocontrolled studies were significantly less severely depressed than those enrolled in the other studies.

Final remission rates were $45 \%$ for venlafaxine (382/851), $35 \%$ for the SSRIs (260/748) and $25 \%$ for placebo (110/ 446). The differences for venlafaxine $v$. SSRIs, venlafaxine $v$. placebo and SSRIs $v$. placebo were highly statistically significant ( $P<0.001$ for all comparisons).

Week-by-week comparisons are illustrated in Fig. 1. Venlafaxine was statistically significantly more effective than the SSRIs from week 2 onwards and versus placebo from week 3 onwards. The SSRI group had a significantly higher remission rate

Table 3 Remission rates (\%) and odds ratios for comparison of intent-to-treat 17 -item Hamilton Rating Scale for Depression (HRSD ${ }_{17}$ ) remission by treatment

\begin{tabular}{|c|c|c|c|c|c|c|}
\hline \multirow[t]{2}{*}{ Study } & \multicolumn{3}{|c|}{ Remission rate (\%) } & \multicolumn{3}{|c|}{ Odds ratio } \\
\hline & Venlafaxine & SSRI & Placebo & Venlafaxine $v$. SSRI & Venlafaxine $v$. placebo & SSRI v. placebo \\
\hline Rudolph \& Feiger, 1999 (Study 21I) & 42 & 23 & 23 & 2.4 & 2.5 & 1.0 \\
\hline Silverstone et al, 1999 (Study 360) & 29 & 28 & 14 & I.I & 2.4 & 2.3 \\
\hline Salinas et al, 1997 (Study 367) & $49^{3}$ & 36 & 38 & 1.9 & 1.6 & I.I \\
\hline Rudolph et al, I998a (Study 372) & 44 & 34 & 23 & 1.5 & 2.5 & 1.7 \\
\hline Clerc et al, 1994 (Study 340) & 55 & 26 & - & 3.5 & - & - \\
\hline Study $347^{2}$ & 51 & 35 & - & 1.9 & - & - \\
\hline Dierick et al, 1996 (Study 348) & 52 & 45 & - & 1.3 & - & - \\
\hline Study $349^{2}$ & 35 & 35 & - & 1.0 & - & - \\
\hline Pooled data & 45 & 35 & 25 & 1.5 & 2.2 & 1.4 \\
\hline
\end{tabular}

I. The remission rates reported here reflect the intent-to-treat, $\mathrm{HRSD}_{17} \leqslant 7$ method used in this paper. The results may therefore differ from those reported in the source manuscripts.

2. Unpublished data on file, Wyeth-Ayerst Research, Philadelphia, PA.

3. The intent-to-treat remission rate on $75 \mathrm{mg} /$ day of venlafaxine $X R$ was $47 \%$ and on $150 \mathrm{mg} /$ day it was $51 \%$.

SSRI, selective serotonin reuptake inhibitor. 
than the placebo group from week 4 onwards.

The results of the eight individual studies are summarised in Table 3. Odds ratios for remission ranged from 1.0 to 3.5 , with an overall odds ratio of $1.5(95 \%$ CI 1.3-1.9). Thus, there was a $50 \%$ greater chance of remission during venlafaxine treatment than during SSRI treatment. Testing for homogeneity of the odds ratios revealed no significant difference $\left(\chi^{2}=8.63\right.$, d.f. $\left.=7, P=0.28\right)$. The sensitivity analysis similarly found that the significant difference between venlafaxine and the SSRIs was not dependent on any one study.

Figure 2 illustrates the results for various subgroup comparisons. The differences between venlafaxine and the SSRIs were statistically significant for all but one of the subgroup analyses. The comparison of venlafaxine and SSRI that included only the four studies that were not placebocontrolled was not statistically significant $(P=0.055)$.

Figure 3 summarises the results according to multiple alternative outcome criteria. Regardless of the definition used, venlafaxine was significantly more effective than the SSRIs, and the SSRIs were significantly more effective than placebo.

In total, $83(9 \%)$ patients were withdrawn from venlafaxine therapy because of side-effects, compared with 57 (7\%) SSRI-treated patients and $10(2 \%)$ patients given placebo (Fisher's exact test, $P=0.001$, venlafaxine $v$. placebo and SSRI $v$. placebo; the venlafaxine $v$. SSRI comparison was not significant, $P=0.185$ ). A total of $33 / 895$ $(4 \%)$ of the venlafaxine-treated patients were withdrawn because of lack of efficacy, compared with $46 / 769(6 \%)$ of patients given an SSRI and 63/453 (14\%) of patients given placebo (Fisher's exact test, $P=0.037$, venlafaxine $v$. SSRI; $P=0.001$, venlafaxine $v$. placebo; $P=0.001$, SSRI $v$. placebo).

\section{DISCUSSION}

\section{Are all antidepressants equally effective?}

It is often stated that the various different classes of antidepressant medication are equally effective (American Psychiatric Association, 1993; Depression Guideline Panel, 1993). However, the methods used to conduct randomised clinical trials render them relatively insensitive to possible

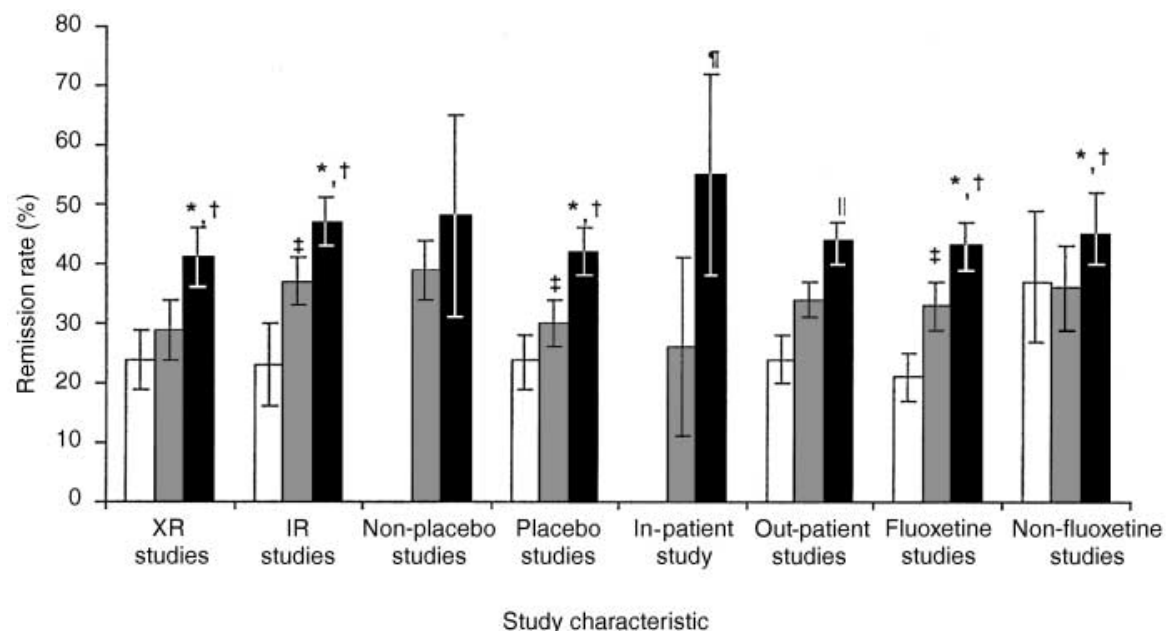

Fig. 2 Remission rates $\left(\mathrm{HRSD}_{17}\right.$ score $\left.\leqslant 7 ; \pm 95 \% \mathrm{Cl}\right)$ in different study types: $* P=0.0009$ (XR studies), $P=0.003$ (immediate-release studies) and $P=0.0003$ (placebo studies) (white bar), venlafaxine (black bar) v. SSRI (grey bar); ${ }^{\dagger} P<0.001$ (XR studies) and $P<0.000$ I (immediate-release studies, placebo studies), venlafaxine $v$. placebo (white bar); ${ }^{\dagger} P=0.028$ (immediate-release studies, placebo studies), SSRI $v$. placebo; $\$ P=0.055$, venlafaxine v. SSRI; ${ }^{\top} \boldsymbol{P}=0.026$ (in-patient study), venlafaxine v. SSRI; $\| \boldsymbol{P}=0.002$ (out-patient studies), venlafaxine v. SSRI. HRSD 17 , I7-item Hamilton Rating Scale for Depression; XR, venlafaxine extended-release formulation; IR, venlafaxine immediate-release (conventional) formulation; SSRI, selective serotonin reuptake inhibitor.

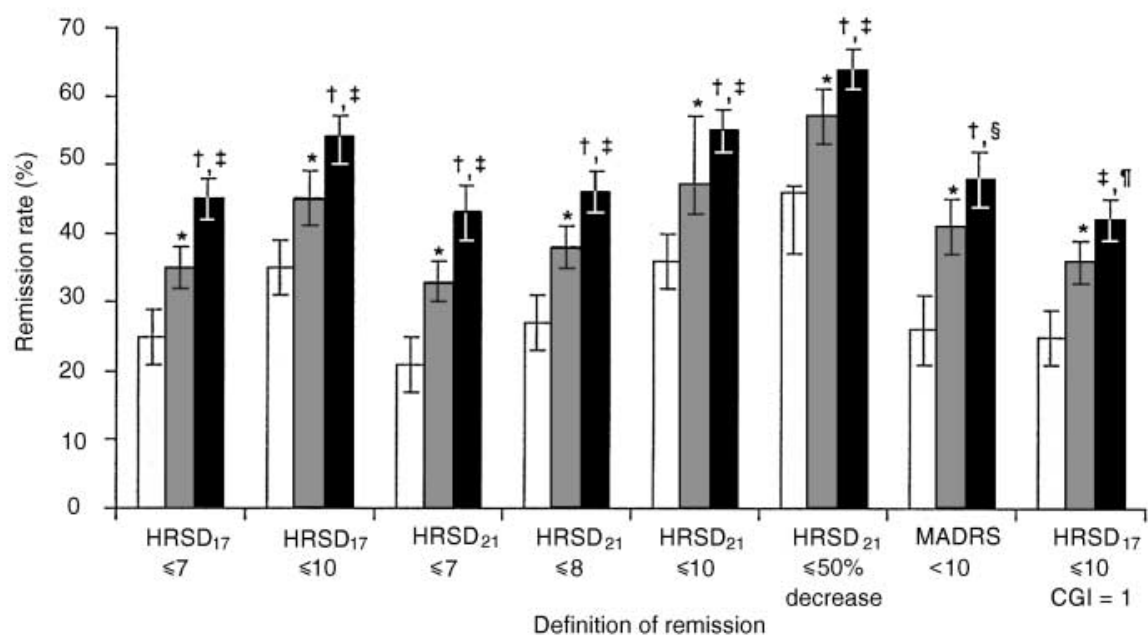

Fig. 3 Final on-therapy remission rates $($ mean, $95 \% \mathrm{Cl})$ with different definitions of remission: $* P<0.00 \mathrm{I}, \mathrm{SSRI}$ (grey bar) v. placebo (white bar); ${ }^{\dagger} P<0.001$, venlafaxine (black bar) v. SSRI; ${ }^{\ddagger} P<0.001$, venlafaxine v. placebo; $\$ P=0.023$, venlafaxine $v$. SSRI; ${ }^{\uparrow} P=0.014$, venlafaxine v. SSRI. HRSD, Hamilton Rating Scale for Depression; SSRI, selective serotonin reuptake inhibitor; MADRS, Montgomery-Åsberg Depression Rating Scale; CGI, Clinical Global Impression scale.

differences between active antidepressants (Thase, 1999). Studies seldom compare groups larger than 120 patients, which does not afford the statistical power to detect modest but still clinically meaningful differences. In addition, multi-site trials may have relatively lower statistical power because of greater patient heterogeneity and lower reliability of diagnoses or dependent measures (Thase, 1999). Moreover, the composition of study groups can have a marked influence on the apparent efficacy of a treatment (Quitkin et al, 1993; Thase et al, 1997).

Meta-analysis provides useful alternative methods to compare active treatments. For example, meta-analyses comparing tricyclic antidepressants and 
SSRIs found differences in subgroup comparisons not apparent in qualitative reviews (Anderson \& Tomenson, 1994; Edwards \& Anderson, 1999). However, because the statistical power of a conventional metaanalysis is determined by the number of studies included, a large number of comparative trials must be available. For comparisons between newer antidepressants, meeting this requirement is often difficult. A second type of meta-analysis, using the data of individual patients participating in a series of related clinical trials, permits powerful comparisons to be made with a much smaller number of studies. Such pooled analyses have been used to document the efficacy of monoamine oxidase inhibitors in the treatment of atypical depression (Quitkin et al, 1993), to examine the association between fluoxetine and suicidality (Beasley et al, 1991), to examine the effects of venlafaxine treatment on blood pressure (Thase, 1998) and to compare psychotherapy and pharmacotherapy (Thase et al, 1997; DeRubeis et al, 1999).
The clinical significance of the magnitude of the differences between venlafaxine and the SSRIs warrants comment. In a conventional antidepressant clinical trial, the size of the study groups is such that statistically significant effects parallel relatively large differences in response rates (i.e. 20$25 \%$ ) that are clearly clinically significant. An analysis of pooled data from an extremely large group of patients, by contrast, would have the statistical power to detect differences in remission rates so small that they would be considered trivial by most (i.e. $3-5 \%$ ). The difference in remission rates observed in our pooled analysis is roughly halfway between these extremes. Given the high prevalence of depression and the staggering associated illness burden, a $10 \%$ advantage in remission rates could have substantial public health implications, particularly if costs and tolerability are comparable. From another perspective, we observed that venlafaxine-treated patients had a $50 \%$ greater chance of attaining remission than patients treated with an SSRI. In terms of the number of patients needed to treat to realise a difference, ten patients would need to be treated with venlafaxine in order to obtain one extra case of remission when compared with the SSRIs. When considered together, these various indicators point to a clinically meaningful difference.

\section{Relationships to pharmacological mechanisms}

It is proposed that the greater efficacy of venlafaxine is the result of reuptake inhibition of both serotonin and noradrenaline. Of course, reuptake inhibition is not essential to therapeutic action and it is possible that medications that potently and selectively affect either serotonergic or noradrenergic neurotransmission may initiate cascades of intracellular events that ultimately modulate the same changes in gene activity (Duman et al, 1997). Nevertheless, several previous studies found clomipramine, another potent dual reuptake inhibitor, to have a significant advantage relative to SSRIs (see Anderson \&

Table 4 Summary of intent-to-treat remission rates of nine venlafaxine-SSRI comparative studies of non-psychotic depression not included in pooled analysis

\begin{tabular}{|c|c|c|c|c|c|c|}
\hline Study & Setting & $\begin{array}{c}\text { Duration } \\
\text { (weeks) }\end{array}$ & Treatment $(n)$ & Dosage (mg/day) & Remission criterion & $\begin{array}{l}\text { ITT remission } \\
\text { rate (\%) }\end{array}$ \\
\hline \multirow[t]{2}{*}{ Tylee et al, 1997} & PC & 12 & Venlafaxine IR (I7I) & 75 & MADRS $\leqslant 6$ & 35 \\
\hline & & & Fluoxetine (I70) & 20 & & 34 \\
\hline \multirow[t]{2}{*}{ McPartlin et al, 1998} & PC & 12 & Venlafaxine XR (183) & 75 & HRSD $\leqslant 6$ & 54 \\
\hline & & & Paroxetine (178) & 20 & & 52 \\
\hline \multirow[t]{2}{*}{ Diaz-Martinez et al, 1998} & OP & 8 & Venlafaxine IR (70) & $75-150$ & $C G I=I$ & 41 \\
\hline & & & Fluoxetine (75) & $20-40$ & & 36 \\
\hline \multirow[t]{4}{*}{ Costa e Silva, 1998' } & OP & 8 & Venlafaxine IR (196) & $75-150$ & $C G I=I$ & 58 \\
\hline & & & Fluoxetine (186) & $20-40$ & & 35 \\
\hline & & & & & HRSD $\leqslant 7$ & 60 \\
\hline & & & & & & 60 \\
\hline \multirow[t]{2}{*}{ Poirier \& Boyer, 1999} & $\mathrm{OP} / \mathrm{IP}$ & 6 & Venlafaxine IR (6I) & $75-300$ & HRSD $<10$ & 37 \\
\hline & & & Paroxetine (62) & $20-40$ & & 18 \\
\hline Alves for the Venlafaxine & OP & 12 & Venlafaxine IR (40) & $75-150$ & HRSD $\leqslant 8$ & 30 \\
\hline Study Group (1999) & & & Fluoxetine (47) & $20-40$ & & II \\
\hline \multirow[t]{2}{*}{ Mehtonen et al, 2000} & OP & 8 & Venlafaxine IR (75) & $75-150$ & HRSD $<10$ & 53 \\
\hline & & & Sertraline (72) & $50-100$ & & 38 \\
\hline \multirow[t]{2}{*}{ Ballús et al, 2000} & OP & 12 & Venlafaxine IR (4I) & $75-150$ & HRSD $<8$ & 59 \\
\hline & & & Paroxetine (43) & $20-40$ & & 31 \\
\hline \multirow[t]{4}{*}{ Tzanakaki et al, 2000' } & IP/PHP & 6 & Venlafaxine IR (55) & 225 & HRSD $<7$ & 41 \\
\hline & & & Fluoxetine IR (54) & 60 & & 36 \\
\hline & & & & & $C G I=I$ & 51 \\
\hline & & & & & & 32 \\
\hline
\end{tabular}

I. Results reported according to two definitions of remission.

CGI, Clinical Global Impression (improvement) scale; HRSD, Hamilton Rating Scale for Depression; IP, psychiatric in-patient; IR, immediate-release formulation; ITT, intent to treat; MADRS, Montgomery-Åsberg Depression Rating Scale; OP, psychiatric out-patient; PC, primary care; PHP, partial hospitalisation programme; XR, extended-release formulation. 
Tomenson, 1994). It appears that relatively higher doses of venlafaxine may be necessary to achieve significant noradrenergic effects, as inferred from in vitro (Muth et al, 1986; Owens et al, 2000), animal (Redrobe et al, 1998) and human (Thase, 1998; Harvey et al, 2000) studies. Consistent with this, there is a clear dose-response relationship for venlafaxine (Rudolph et al, 1998b) and patients who fail to benefit from $75 \mathrm{mg} /$ day often respond to higher doses (Dierick et al, 1996; Costa e Silva, 1998; Diaz-Martinez et al, 1998; Mehtonen et al, 2000). Therefore, it is likely that the difference in efficacy between venlafaxine and SSRIs is dose dependent. Unfortunately, the flexible dose schedules utilised in five of the studies included in our metaanalysis precluded a valid examination of dose-response relationships. Research using modern molecular biological techniques would help to confirm that the greater antidepressant efficacy of venlafaxine is directly linked to a dual reuptake-inhibitory mechanism of action.

\section{Review of other comparative studies}

The most important limitation of a pooled analysis is that the results can be biased by selection of a non-representative group of studies. Our data set included all eight comparative studies conducted by the Wyeth-Ayerst Clinical Research and Development department; no studies were excluded. However, there are at least 12 other studies comparing venlafaxine and SSRIs for treatment of non-psychotic depression. Among these, three recently completed studies (double-blind, placebo- and fluoxetine-controlled trials in out-patients with melancholia, in-patients with melancholia or elderly patients) could not be included because data analyses were not complete. The remaining nine published studies were not included because we did not have access to the original data sets (see Table 4).

It is possible that the inclusion of these additional trials would have affected the findings of the current pooled analysis. We therefore conducted a qualitative review of the nine published studies. Two studies found no evidence of differences in response or remission rates (Tylee et al, 1997; McPartlin et al, 1998). These studies were conducted in primary care clinics and compared the minimum therapeutic dosages of venlafaxine $(75 \mathrm{mg} /$ day $)$ and fluoxetine (20 mg/day) (Tylee et al, 1997) or paroxetine $(20 \mathrm{mg} /$ day) (McPartlin et al, 1998).

Two studies reported non-significant differences (Diaz-Martinez et al, 1998; Alves et al, 1999). Diaz-Martinez et al (1998) reported that $41 \%$ of 70 patients treated with venlafaxine $(75-150 \mathrm{mg} /$ day $)$ remitted during an open-label but randomised 8 -week trial, as compared with $36 \%$ of 75 patients treated with fluoxetine (20$40 \mathrm{mg} /$ day). The difference was $30 \%$ (i.e. $50 \%$ v. 20\%) among those who received either $150 \mathrm{mg} /$ day of venlafaxine $(n=18)$ or $40 \mathrm{mg} /$ day of fluoxetine $(n=15)$. However, this numerically large difference was not statistically significant $(P=0.07)$ in such a small subsample. Alves et al (1999) found a $19 \%$ difference $(30 \% v$. $11 \%)$ in remission rates favouring venlafaxine $(75-150 \mathrm{mg} /$ day $)$ over fluoxetine (20-40 mg/day), which again was not statistically significant in a relatively small study ( $n=87)$.

Two studies reported inconsistent findings, with significant results favouring venlafaxine over fluoxetine using a global definition of remission but not according to the final HRSD score (see Table 4). Costa e Silva (1998) observed remission rates of $58 \%$ for venlafaxine $(75-150 \mathrm{mg} /$ day) and $35 \%$ for fluoxetine $(20-40 \mathrm{mg} /$ day) using a CGI numeric score of 1 to define remission, although $60 \%$ of the patients in each group remitted when an HRSD score of $\leqslant 7$ was the criterion. Tzanakaki et al (2000) similarly found that the groups were comparable using an HRSD criterion $(<7)$ but significantly different according to the CGI definition (see Table 4).

The three remaining studies found significant differences favouring venlafaxine; these studies all utilised maximum doses of $\geqslant 150 \mathrm{mg} /$ day. Ballús et al (2000) observed remission rates of $59 \%$ for venlafaxine $(75-$ $150 \mathrm{mg} /$ day) and $31 \%$ for paroxetine (20$40 \mathrm{mg} /$ day). Mehtonen et al (2000), defining remission as a score of $<10$ on the 21 item version of the HRSD, reported rates of $68 \%$ for venlafaxine $(75-150 \mathrm{mg} /$ day $)$ and $45 \%$ for sertraline $(50-100 \mathrm{mg} /$ day $)$ among completers at week 8 . Poirier $\&$ Boyer (1999) enrolled only patients who had failed to respond to at least two previous trials of antidepressants. About $75 \%$ had not responded to a prior course of SSRI therapy. They found a $19 \%$ advantage $(37 \% v .18 \%)$ in remission rates in favour of venlafaxine $(200-300 \mathrm{mg} /$ day $)$ relative to paroxetine $(20-40 \mathrm{mg} /$ day $)$.
Although these studies used various durations of treatment and definitions of remission, two conclusions are evident. First, there is no evidence that venlafaxine is more effective than the SSRIs at minimum therapeutic doses. Second, among the studies that permitted a venlafaxine dosage of $\geqslant 150 \mathrm{mg} /$ day, there was a $14.4 \%$ average difference (range 5-23\%) in remission rates favouring venlafaxine. It appears that the results of our pooled analysis would not have changed if we could have included these studies.

\section{Other limitations}

The generalisability of the results of a group of controlled clinical trials, like those of the individual studies, is limited by the exclusion of patients with more complex conditions, such as significant psychiatric and medical comorbidities. Although this lessens the relevance of these results to clinical practice, there is no reason to suspect that this exclusivity favours venlafaxine over the SSRIs. Other potential shortcomings of pooled analyses include problems with the reliability of dependent measures and the possibility that the results may be influenced by the data from one or two particularly large studies. We found significant differences between SSRIs and placebo, however, which indicates that the 'assay sensitivity' (Leber, 1991) of the pooled analysis was, at the least, sufficient to overcome measurement error. We also confirmed that the differences were not attributable to any particular study and extended across multiple definitions of remission.

Three more specific limitations can be considered. First, the SSRIs were lumped together as a class. Although there is no evidence that any SSRI is more effective than another, they are not truly interchangeable and some patients respond poorly to one SSRI but well to another (Edwards \& Anderson, 1999). In this respect, our pooled analysis included a disproportionate number of patients treated with fluoxetine. The studies listed in Table 4 provide a broader range of comparisons and, in aggregate, yielded similar results. Nevertheless, among the 17 comparative studies included in the pooled analysis or summarised in Table 4, there is only one study each utilising fluvoxamine or sertraline and, to date, there are no studies of citalopram. 
Second, all of the studies were short term. It is possible that a longer treatment period could have resulted in comparable remission rates.

Third, none of the studies used in the pooled analysis excluded patients who had failed to respond to other SSRIs. Because several SSRIs were already widely available when these studies were conducted, it is possible that the advantage observed for venlafaxine was delimited to a subgroup of patients who had previously failed trials of other SSRIs (see, for example, Poirier \& Boyer, 1999).

\section{REFERENCES}

Alves, C., for the Venlafaxine Study Group (1999) Efficacy and tolerability of venlafaxine and fluoxetine in outpatients with major depression. Primary Care Psychiatry, 5, 57-63.

American Psychiatric Association (1987) Diagnostic and Statistical Manual of Mental Disorders (3rd edn, revised) (DSM-III-R). Washington, DC: APA.

— (1993) Practice guideline for major depressive disorder in adults. American Journal of Psychiatry, $\mathbf{1 5 0}$ (suppl. 4), I-26.

- (1994) Diagnostic and Statistical Manual of Mental Disorders (4th edn) (DSM-IV). Washington, DC: APA

Anderson, I. M. \& Tomenson, B. M. (1994) The efficacy of selective serotonin re-uptake inhibitors in depression: a meta-analysis of studies against tricyclic antidepressants. Journal of Psychopharmacology, 8, 238249.

Ballús, C., Quiros, G., de Flores, T., et al (2000) The efficacy and tolerability of venlafaxine and paroxetine in outpatients with depressive disorder or dysthymia. International Clinical Psychopharmacology, I5, 43-48.

Beasley, C. M., Jr., Dornseif, B. E., Bosomworth, J. C., et al (1991) Fluoxetine and suicide: a meta-analysis of controlled trials of treatment for depression. British Medical Journal, 303, 685-692.

Breslow, N. E. \& Day, N. E. (1980) Statistical Methods in Cancer Research. Volume I. The Analysis of Case-Control Studies. Lyons: IARC Scientific Publications.

Clerc, G. E., Ruimy, P., Verdeau-Paillès, J., et al (1994) A double-blind comparison of venlafaxine and fluoxetine in patients hospitalized for major depression and melancholia. International Clinical Psychopharmacology, 9, 139-143.

Costa e Silva, J. (1998) Randomized, double-blind comparison of venlafaxine and fluoxetine in outpatients with major depression. Journal of Clinical Psychiatry, 59, 352-357.

Depression Guideline Panel (1993) Depression in Primary Care. Volume 2. Treatment of Major Depression. Clinical Practice Guideline No. 5, AHCPR Publication No. 93-055I. Rockville, MD: US Department of Health and Human Services, Public Health Service, Agency for Health Care Policy and Research.

DeRubeis, R. J., Gelfand, L. A., Tang, T. Z., et al (1999) Medication versus cognitive behavior therapy for severely depressed outpatients: meta-analysis of four randomized comparisons. American Journal of Psychiatry, 156, 1007-1013.

\section{CLINICAL IMPLICATIONS}

- Patients treated with venlafaxine had a $10 \%$ greater chance of remission than those treated with SSRIs (45\% v. 35\%).

- Onset of remission occurred I-2 weeks earlier for venlafaxine-treated patients.

Doses of $\geqslant 150 \mathrm{mg} /$ day venlafaxine may be necessary to maximise the likelihood of remission.

\section{LIMITATIONS}

- Results of meta-analysis may be affected by the quality of the individual studies.

- Generalisability is limited by the exclusivity of clinical trial enrolment.

- There is not a sufficient number of studies to compare venlafaxine with specific SSRIs other than fluoxetine.

MICHAEL E. THASE, MD, University of Pittsburgh School of Medicine, Western Psychiatric Institute and Clinic, Pittsburgh, PA, A. RICHARD ENTSUAH, PhD, RICHARD L. RUDOLPH, MD, Clinical Research and Development, Wyeth-Ayerst Research, Philadelphia, PA, USA

Correspondence: Michael E. Thase, Professor of Psychiatry, University of Pittsburgh School of Medicine, Western Psychiatric Institute and Clinic, 38II O'Hara Street, Pittsburgh, PA I52I3-2593, USA

(First received 31 January 2000, final revision 10 August 2000, accepted 14 August 2000)

Diaz-Martinez, A., Benassinni, O., Ontiveros, A., et al (1998) A randomized, open-label comparison of venlafaxine and fluoxetine in depressed outpatients. Clinical Therapeutics, 20, 467-476.

Dierick, M., Ravizza, L., Realini, R., et al (1996) A double-blind comparison of venlafaxine and fluoxetine for treatment of major depression in outpatients. Progress in Neuropsychopharmacology and Biological Psychiatry, 20, 57-7I.

Duman, R. S., Heninger, G. R. \& Nestler, E. J. (1997) A molecular and cellular theory of depression. Archives of General Psychiatry, 54, 597-606.

Edwards, J. G. \& Anderson, I. (1999) Systematic review and guide to selection of selective serotonin reuptake inhibitors. Drugs, 54, 507-533.

Fava, G. A., Grandi, S., Zielezny, M., et al (1996) Four-year outcome for cognitive behavioral treatment of residual symptoms in major depression. American Journal of Psychiatry, 153, 945-947.

Frank, E., Prien, R. F., Jarrett, R. B., et al (1991) Conceptualization and rationale for consensus definitions of terms in major depressive disorder. Remission, recovery, relapse, and recurrence. Archives of General Psychiatry, 48, 85I-855.

Hamilton, M. (1960) A rating scale for depression. Journal of Neurology, Neurosurgery and Psychiatry, 23. $56-62$.

Harvey, A.T., Rudolph, R. L. \& Preskorn, S. H. (2000) Evidence of the dual mechanisms of action of venlafaxine. Archives of General Psychiatry, 57, 503-509.

Leber, P. (199I) Is there an alternative to the randomized controlled trial? Psychopharmacology Bulletin, 27, 3-8.
McPartlin, G. M., Reynolds, A., Anderson, C., et al (1998) A comparison of once-daily venlafaxine $X R$ and paroxetine in depressed outpatients treated in general practice. Primary Care Psychiatry, 4, 127-132.

Mehtonen, O.-P., Behnke, K., Søgaard, J., et al (2000) Randomized, double-blind comparison of venlafaxine and sertraline in outpatients with major depression. Journal of Clinical Psychiatry, 61, 95-100.

Miller, I. W., Keitner, G. I., Schatzberg, A. F., et al (1998) The treatment of chronic depression. Part 3: psychosocial functioning before and after treatment with sertraline or imipramine. Journal of Clinical Psychiatry, 59, 608-619.

Montgomery, S. A. \& Åsberg, M. (1979) A new depression scale designed to be sensitive to change. British Journal of Psychiatry, 134, 382-389.

Muth, E. A., Haskins, J.T., Moyer, J. A., et al (1986) Antidepressant biochemical profile of the novel bicyclic compound Wy-45,030, an ethyl cyclohexanol derivative. Biochemical Pharmacology, 35, 4493-4497.

National Institute of Mental Health (1985) Clinica Global Impressions. Psychopharmacology Bulletin, 2I, 839-843.

Owens, M. J., Morgan, W. N., Plott, S. J., et al (1997) Neurotransmitter receptor transporter binding profile of antidepressants and their metabolites. Journal of Pharmacology and Experimental Therapeutics, 283. 1305-1322.

Poirier, M.-F. \& Boyer, P. (1999) Venlafaxine and paroxetine in treatment-resistant depression. Doubleblind, randomised comparison. British Journal of Psychiatry, 175, 12-16. 
Prien, R. F., Carpenter, L. L. \& Kupfer, D. J. (1991) The definition and operational criteria for treatment outcome of major depressive disorder: a review of the current research literature. Archives of General Psychiatry, 48, 796-800.

Quitkin, F. M., Stewart, J.W., McGrath, P. J., et al (1993) Columbia atypical depression. A subgroup of depressives with better response to $\mathrm{MAOI}$ than to tricyclic antidepressants or placebo. British journal of Psychiatry, 163 (suppl. 2I), 30-34.

Redrobe, J. P., Bourin, M., Colombel, M. C., et al (1998) Dose-dependent noradrenergic and serotonergic properties of venlafaxine in animal models indicative of antidepressant activity. Psychopharmacology 138, I-8.

Rothman, K. J. (1986) Modern Epidemiology. Boston, MA: Little, Brown \& Co.

Rudolph, R. L. \& Feiger, A. D. (1999) A double-blind randomized, placebo-controlled trial of once-daily venlafaxine extended release $(X R)$ and fluoxetine for the treatment of depression. Journal of Affective Disorders, 56, $|7|-|8|$.
_, Entsuah, R., Aguiar, L., et al (1998a) Early onset of antidepressant activity of venlafaxine compared with placebo and fluoxetine in outpatients in a double-blind study. European Neuropsychopharmacology, 8 (suppl. 2), SI42.

_ , Fabre, L. F., Feighner, J. P., et al (1998b) A

randomized, placebo-controlled, dose-response trial of venlafaxine hydrochloride in the treatment of major depression. Journal of Clinical Psychiatry, 59, 116-122.

Salinas, E., for the Venlafaxine XR 367 Study Group (1997) Once-daily extended release $(X R)$ venlafaxine versus paroxetine in outpatients with major depression. Biological Psychiatry, 42 (suppl. I), 244S.

Silverstone, P. H., Ravindran, A., for the Venlafaxine XR 360 Study Group (1999) Once-daily venlafaxine extended release $(X R)$ compared with fluoxetine in outpatients with depression and anxiety. Journal of Clinical Psychiatry, 60, 22-28.

Thase, M. E. (1998) Effects of venlafaxine on blood pressure: a meta-analysis of original data from 3744 depressed patients. Journal of Clinical Psychiatry, 59, 502-508.
- (1999) How should efficacy be evaluated in randomized clinical trials of treatments for depression? Journal of Clinical Psychiatry, 60 (suppl. 4), 23-32.

_ , Simons, A. D., McGeary, J., et al (1992) Relapse after cognitive behavior therapy of depression: potentia implications for longer courses of treatment. American Journal of Psychiatry, 149, 1046-1052.

_ , Greenhouse, J. B., Frank, E., et al (1997)

Treatment of major depression with psychotherapy or psychotherapy-pharmacotherapy combinations. Archives of General Psychiatry, 54, 1009-1015.

Tylee, A., Beaumont, G., Bowden, M. W., et al (1997) A double-blind, randomized, 12-week comparison study of the safety and efficacy of venlafaxine and fluoxetine in moderate to severe major depression in general practice. Primary Care Psychiatry, 3, 51-58.

Tzanakaki, M., Guazzelli, M., Nimatoudis, l., et a (2000) Increased remission rates with venlafaxine compared with fluoxetine in hospitalized patients with major depression and melancholia. International Clinical Psychopharmacology, 15, 29-34. 